\title{
Extinction efficiencies of coated absorbing aerosols measured by cavity ring down aerosol spectrometry
}

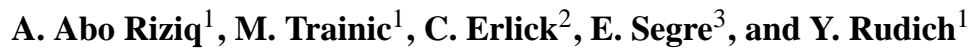 \\ ${ }^{1}$ Department of Environmental Sciences, Weizmann Institute, Rehovot, 76100, Israel \\ ${ }^{2}$ Department of Atmospheric Sciences, The Hebrew University of Jerusalem, Jerusalem, 91904, Israel \\ ${ }^{3}$ Physics Services, Weizmann Institute, Rehovot, 76100, Israel
}

Received: 26 November 2007 - Published in Atmos. Chem. Phys. Discuss.: 17 December 2007

Revised: 22 February 2008 - Accepted: 28 February 2008 - Published: 26 March 2008

\begin{abstract}
In this study, we measure the extinction efficiency at $532 \mathrm{~nm}$ of absorbing aerosol particles coated with a nonabsorbing solid and liquid organic shell with coating thickness varying between 5 and $100 \mathrm{~nm}$ using cavity ring down aerosol spectrometry. For this purpose, we use nigrosin, an organic black dye, as a model absorbing core and two nonabsorbing organic substances as shells, glutaric acid (GA) and Di-Ethyl-Hexyl-Sebacate (DEHS). The measured behavior of the coated particles is consistent with Mie calculations of core-shell particles. Errors between measured and calculated values for nigrosin coated with GA and DEHS are between $0.5 \%$ and $10.5 \%$ and between $0.5 \%$ and $9 \%$, respectively. However, it is evident that the calculations are in better agreement with the measured results for thinner coatings. Possible reasons for these discrepancies are discussed.
\end{abstract}

\section{Introduction}

Optical properties of aerosols, such as the complex refractive index, determine their extinction and hence their direct effect on climate through scattering and/or absorption of incoming solar and outgoing terrestrial radiation (Forster et al., 2007; Kaufman and Fraser, 1997; Kaufman et al., 2002; Koren et al., 2005; Ramanathan et al., 2005; Ramanathan et al., 2007). Scattering and absorption by atmospheric aerosols leads to some of the largest uncertainties in quantifying changes in the climate system. The optical properties of aerosols are controlled by their chemical composition and physical characteristics, such as shape and morphology. Furthermore, the ways in which the various chemicals are mixed within the aerosol, e.g., whether the aerosol is externally mixed, ho-

Correspondence to: Y. Rudich (yinon.rudich@weizmann.ac.il) mogenously internally mixed, or heterogeneously internally mixed, influence its optical properties. It has been shown that in the atmosphere, aerosols are often heterogeneously internally mixed, such as a core coated by adsorbed material (Chýlek et al., 1996; Falkovich et al., 2004; Guazzotti et al., 2001; Lesins et al., 2002; Res et al., 2006; Zhang et al., 2005). The coating can be organic, inorganic, or a mixture. For example, solid black carbon (BC) is less soluble than most aerosol components and relatively inert. Therefore, it is often heterogeneously mixed with organic carbon (OC) or other substances, and has a core plus shell structure, i.e., it is in a coated form. Calculations involving elemental carbon (EC) mixed with other chemical compounds have shown that the most realistic treatment for the internal mixture is the heterogeneous core plus shell model (Jacobson, 2000). It has been shown that differences between the optical properties of internally and externally mixed $\mathrm{BC}$ are significant, and that internally mixed $\mathrm{BC}$ is a stronger absorber than in the externally mixed $\mathrm{BC}$ and even more than $\mathrm{BC}$ alone (Chung and Seinfeld, 2002; Fuller et al., 1999; Jacobson, 2000; Lesins et al., 2002). Coated soot has been observed in field studies (Gelencser, 2004; Res et al., 2006). Recent in situ measurements have shown that as $\mathrm{BC}$ ages in the atmosphere, it acquires thick coatings, and such thickly coated BC particles are found throughout the atmospheric column up to the upper troposphere (Res et al., 2006). Furthermore, the coatings enhance light absorption by the ambient $\mathrm{BC}$ column by at least $30 \%$, suggesting that the microphysical state of aerosols in the atmosphere have profound effects on their optical properties (Res et al., 2006). Mineral dust is also often coated by organic compounds that condense on the particles during transport (Falkovich et al., 2004; Maria et al., 2004; Russell et al., 2002). Reactions of inorganic acids with mineral dust components such as calcium carbonate can also lead to a formation of a layer over the unreacted core (Goodman et al., 2000; Krueger et al., 2004; Krueger et al., 2003; Laskin

Published by Copernicus Publications on behalf of the European Geosciences Union. 


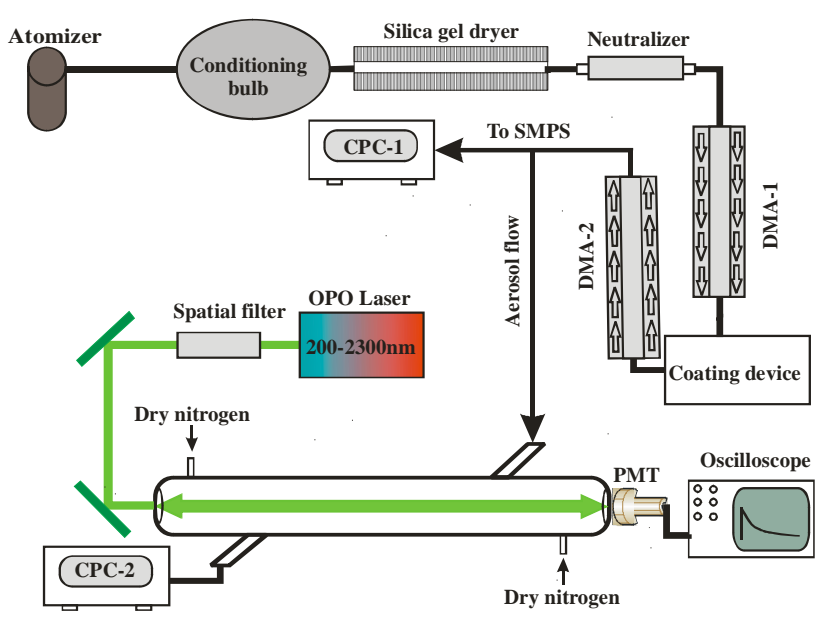

Fig. 1. A schematic representation of the experimental setup. The particles are nebulized in the atomizer and pass through the $3-\mathrm{L}$ volume conditioning bulb. They continue to the diffusion dryers, from which they pass through the neutralizer to DMA-1, continue through the coating device, and are then measured by SMPS, comprised of the DMA-2 and CPC-1. After SMPS measurements, the DMA-2 is used for a second size selection (double DMA) from which the particles pass to the CRD-AS system, comprised of the OPO laser as the light source, the cavity where the decay takes place, and CPC-2 for particle counting.

et al., 2005). This layer is often more hygroscopic and may affect the optical properties of the particle as a result of its chemical composition as well as influencing the adsorption of water, which may change the particle shape.

$\mathrm{BC}$ is the most strongly absorbing and one of the strongest scattering carbonaceous substances among atmospheric aerosols. Hence, it has substantial effect on the climate (Bond and Bergstrom, 2006; Chung and Seinfeld, 2002; Fuller et al., 1999; Kirchstetter et al., 2004; Lesins et al., 2002; Sun et al., 2007). To understand the effect of strongly absorbing aerosols on climate, it is important to characterize the optical properties in pure and mixed states. Black carbon is rarely found in its elemental form in the atmosphere. It mostly appears in the form of soot, which is an internal mixture of black carbon with organic carbon, inorganic substances, trace metals, and other elements (Gelencser, 2004). Soot is usually found in the form of aggregates of primary soot spheres (Fuller et al., 1999; Gelencser, 2004), such that soot particles are not strictly spherical. Nevertheless, the effect of soot on climate is often modeled by a core plus shell Mie calculation. To approach a proper evaluation of the possible climatic effect of coated particles such as soot and the performance of basic Mie scattering calculations, we performed experiments with a proxy that is both strongly absorbing and spherical. In this study we employ nigrosin, a black organic dye, internally mixed with organic carbon, as a proxy for strongly absorbing aerosol in a heterogeneously mixed core-shell state (Bond and Bergstrom, 2006; Garvey and Pinnick, 1983; Lack et al., 2006; Shi et al., 2005).
We measure the 532-nm extinction efficiencies of particles comprised of a nigrosin core surrounded by an organic shell. The organic shells used in this study are glutaric acid (GA) and Di-Ethyl-Hexyl-Sebacate (DEHS), which are proxies for non-absorbing organic compounds found abundantly in both anthropogenic and biogenic atmospheric aerosols. These coatings represent both solid and liquid organic coatings. We then compare the measured results to those calculated based on Mie theory for particles with core-shell morphology (Toon and Ackerman, 1981; Bohren and Huffman, 1983).

\section{Methods}

2.1 Aerosol generation, coating and retrieval of extinction efficiency

In order to produce coated particles with well-defined coating thicknesses and to determine their extinction, a system comprised of three main components was constructed: seed aerosol generation and size classification, coating system, and a cavity ring down aerosol spectrometer (CRD-AS) for precisely measuring the extinction (see Fig. 1).

\subsubsection{Seed aerosol generation and selection}

An aqueous solution of nigrosin was nebulized using a constant output atomizer (TSI-3076) with dry particle-free nitrogen. The droplets were dried in two silica gel column dryers $(\mathrm{RH}<3 \%)$, yielding a polydisperse aerosol distribution. The aerosols were neutralized (TSI 3012A) to obtain an equilibrium charge distribution. Size-selected monodisperse aerosol flow was generated using an electrostatic classifier (TSI Differential Mobility Analyzer (DMA-1)) operating with 5 SLM dry nitrogen sheath flow and 0.5 SLM sample flow. The size-selected monodisperse particles were directed into the coating device (see below). The coated particles were analyzed to examine their size distribution and number concentration using a scanning mobility particle sizer (SPMS, DMA-2 and CPC-1) as shown in Fig. 1. Afterwards, the particles were size selected by DMA-2 in order to narrow the resulting aerosol size distribution and to select the average coating thickness. The aerosol flow was diluted for precise control of the particle number concentration and total flow that entered the CRD-AS cell ( 0.8 SLM).

\subsubsection{Coating of seed aerosol}

A schematic drawing of the coating device is shown in Fig. 2. Briefly, the coated particles were generated by organic vapor deposition onto injected size-selected nigrosin seed particles inside a temperature controlled coating device (Roselli, 2006). The temperature of the vessel was kept stable at $\pm 0.1^{\circ} \mathrm{C}$. The coating thickness was controlled by varying the temperature of the vessel and the flow rate of the aerosol in the vapor-saturated air. A flow of size-selected nigrosin seeds 
was directed into the device through an inlet that was situated above the GA surface. The temperature required for vaporizing GA and subsequent coating on nigrosin seeds was between 80 and $100^{\circ} \mathrm{C}$ for coating layers of diameters between $10 \mathrm{~nm}$ and $150 \mathrm{~nm}$, respectively. The flow of dry nitrogen varied between 20 and $40 \mathrm{~cm}^{3} \mathrm{~min}^{-1}$. For DEHS, the required temperature was between 90 and $115^{\circ} \mathrm{C}$ for coating layers between 10 and $150 \mathrm{~nm}$, respectively. A similar system for coating with organic substances has been tried and was found to be efficient and accurate (Kousaka et al., 1995).

\subsubsection{Measuring aerosol extinction by CRD-AS}

The CRD-AS system consists of a cavity capable of measuring aerosol extinction in the visible $(510-550 \mathrm{~nm})$ range, using highly reflective plano-concave mirrors (curvature radii of $1 \mathrm{~m}$ and $99.995 \%$ reflectivity at $532 \mathrm{~nm}$ (Los Gatos, USA)) mounted at the two sides of a $93 \mathrm{~cm} \mathrm{3/4"} \mathrm{stainless} \mathrm{steel} \mathrm{tube.}$ The system was described in detail elsewhere (Dinar et al., 2008; Riziq et al., 2007) and only short description is given here. A small purge flow of dry particle-free nitrogen $(0.07$ and $0.1 \mathrm{~L} \mathrm{~min}^{-1}$ ) is introduced in front of each mirror and prevents mirror contamination by particle deposition. The aerosol flow enters the cavity through four tubes at $45^{\circ}$ designed to ensure good mixing and even concentration of the particles throughout the cavity (Lack et al., 2006). The particles exit the cavity with a flow rate of $0.95 \mathrm{~L} \mathrm{~min}^{-1}$ in a similar configuration. The length of the cavity occupied by particles is about $68 \mathrm{~cm}$. The particle concentration is determined by a condensation particle counter (CPC, TSI 3022A) taking into account the dilution inside the cavity as a result of the purge flow of dry nitrogen on the mirrors. Only the mode size of the injected aerosol was used for calculations. This is a robust measurement and the effect of a distribution of sizes on the retrieval accuracy was thoroughly discussed in a recent a paper by Spindler et al. (2007).

Laser light at $532 \mathrm{~nm}$ is produced by doubling a Nd:YAG laser $(10 \mathrm{~Hz}, 3-6 \mathrm{~ns}$, Ekspla). The laser beam is directed through a spatial filter consisting of two lenses with focal lengths of $5 \mathrm{~cm}$ and $10 \mathrm{~cm}$, respectively, and a $100-\mu \mathrm{m}$ pinhole in the common focus of the lenses. The beam diameter in front of the cavity is about $1 \mathrm{~mm}$, with energy of 1$1.5 \mathrm{~mJ}$ per pulse. The laser intensity emerging from the CRD cell is measured with a photomultiplier (Hamamatsu H678002 ), and the resulting signal is fed into a digital oscilloscope (LeCroy, model 9361, $300 \mathrm{MHz}$ ). The digitized data for each laser pulse is transferred and stored in a computer. The decay time for a cavity filled with particle-free dry nitrogen $\left(\tau_{0}\right)$ is $60 \mu$ s for the 532-nm wavelength.

\subsection{Aerosol sampling and AFM imaging}

The aerosol particles were sampled using a 10-stage MicroOrifice Uniform Deposition Impactor (MOUDI - Model 110 with rotator, MSP Corporation, Shoreview, MN, USA) and

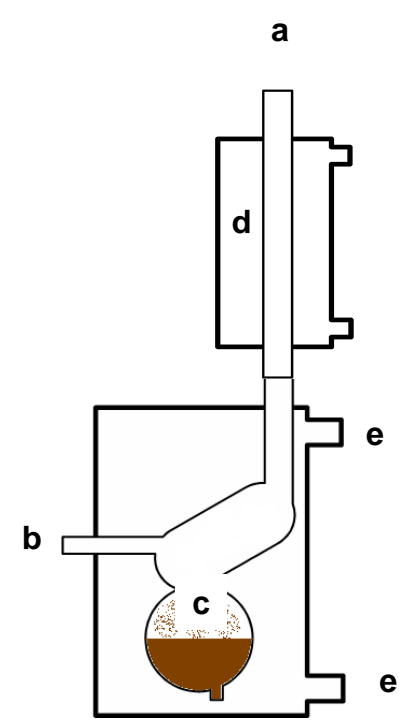

Fig. 2. A schematic drawing of the coating device (Roselli, 2006). (a) particles exit, (b) particles enter, (c) heated reservoir of organic material, (d) condenser, and (e) heating fluid connection.

analyzed with an atomic force microscope (AFM) in order to verify that they have a spherical shape. Mica substrates were placed on the aluminum surfaces, which were positioned on the relevant stages of the impactor. For the size range (size represents the diameter of particles and the various fractions (core and shell) throughout this entire paper) of the aerosols generated, we used stages 6,7 , and 8, which correspond to the size ranges of $560-1000 \mathrm{~nm}, 320-560 \mathrm{~nm}$, and $180-$ $320 \mathrm{~nm}$, respectively. The impactor sampled the aerosols immediately following the DMA-2. Aerosol particles were collected for up to $1.5 \mathrm{~h}$. The substrates were placed in a plastic box and sealed with parafilm to prevent possible contamination from the ambient air.

The samples were analyzed by AFM in ambient conditions, as the AFM does not require vacuum conditions that could have caused both the glutaric acid and the DEHS to evaporate. For technical reasons, three different AFM instruments were used. For most of the samples, we used two AFM P47 instruments (NT-MDT, Zelenograd, Russia) with a 13$\mu \mathrm{m}$ scanner, Nikel coated silicon $70-\mathrm{kHz}$ resonance probes with nominal spring constant $\left(K=1 \mathrm{~N} \mathrm{~m}^{-1}\right)$, used in semicontact (tapping) mode. The scan size was $13 \mu \mathrm{m}$ (full range) with scanning rates between 0.25 and $2 \mathrm{~Hz}$ and a spatial resolution of 256 pixels per length. The third AFM used, MultiMode (Digital Instruments, Vecco Instruments, USA), has the same specifications but with a spatial resolution of 512 pixels per length. For each sample, at least three locations were analyzed in order to detect any inhomogeneities in the particles' deposition. 


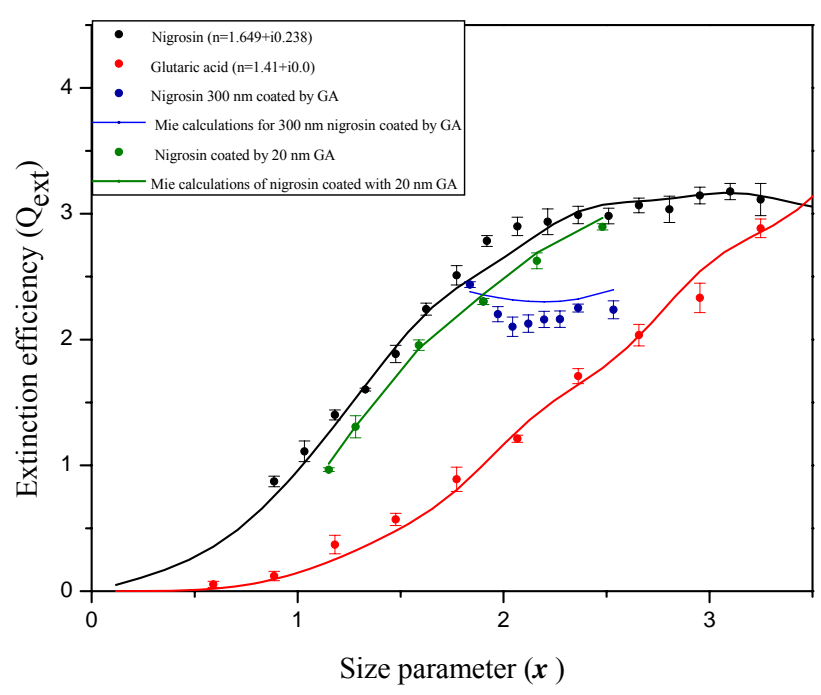

Fig. 3. The measured and calculated extinction efficiencies $\left(Q_{\text {ext }}\right)$ of nigrosin coated with GA as a function of size parameter $(x)$.

\subsection{Mie calculations for coated particles}

The refractive indices at $532 \mathrm{~nm}$ of the substances used in the Mie calculations were taken from CRD-AS measurements of aerosols composed of the pure substances. For glutaric acid, a value of $n=1.41+i 0.0$ taken from our previous measurements (Riziq et al., 2007) was used, and for nigrosin, a value of $n=1.649+i 0.238$ (Dinar et al., 2008) was used. This value is consistent with prior reports of refractive indices for nigrosin, namely $n=1.67+0.26 i$ (Garvey and Pinnick, 1983) and $n=1.7+0.31 i$ (Lack et al., 2006). For DEHS (a derivative of Dioctyl Sebacate (DOS)), a value of $n=1.455+i 0.0$ was used, based on previous CRD measurements of DOS by Pettersson et al. (2004).

The subroutine DMiLay (Toon and Ackerman, 1981) and a version of bhcoat (Bohren and Huffman, 1983) adapted for Matlab by C. Mätzler were used to compute the extinction efficiencies of the coated particles. These codes compute the scattering parameters for a plane electromagnetic wave incident on a stratified dielectric sphere, i.e., a spherical core surrounded by a spherical shell. Unlike mixing rules, these codes are exact implementations of Mie theory, where the core and shell retain their individual refractive indices during the computation. DMiLay is a double precision code designed to accurately handle large size parameters, thin shells, and large imaginary refractive indices, and to avoid the ill-conditioning common to other core plus shell codes, although bhcoat produced the same results to the number of decimal places reported here.

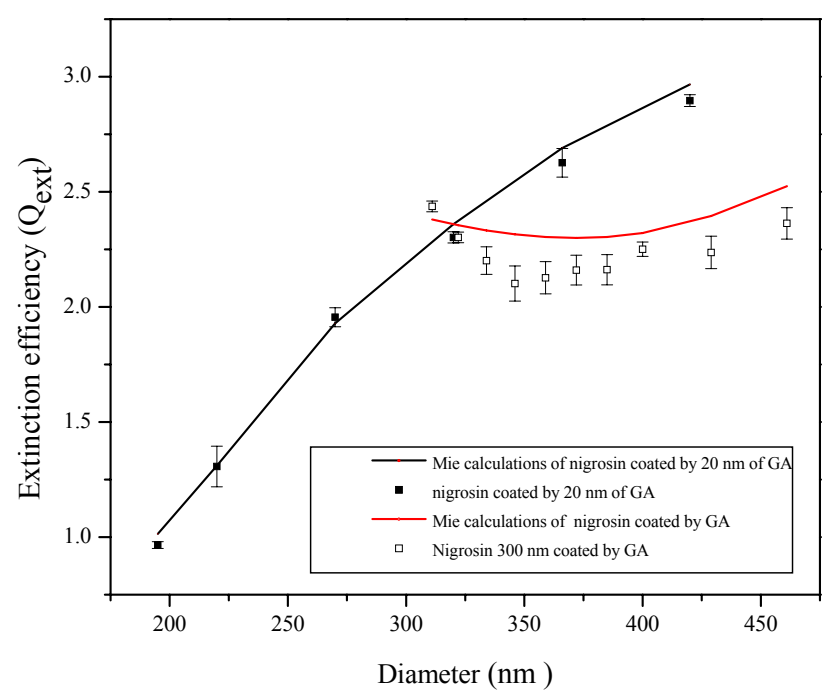

Fig. 4. The measured and calculated extinction efficiencies $\left(Q_{\text {ext }}\right)$ of nigrosin coated with GA as a function of particle size (diameter).

\section{Results}

\subsection{Nigrosin coated with GA}

In Fig. 3, the measured extinction efficiency ( $\left.Q_{\text {ext }}\right)$ as a function of particle size parameter $(x=\pi \lambda / D$, where $\lambda$ is the wavelength of light and $D$ is the particle's diameter) is shown for pure nigrosin (black dots) along with the corresponding Mie calculation (Dinar et al., 2008) (solid black line), for pure glutaric acid (red dots) along with the corresponding Mie calculation (Riziq et al., 2007) (solid red line), for nigrosin of various sizes coated with a 20-nm glutaric acid shell (green dots) along with the corresponding Mie calculation (green line), and for 300-nm nigrosin coated with various thicknesses of glutaric acid (blue dots) along with the corresponding Mie calculation (blue line). In Fig. 4, the measured $Q_{\text {ext }}$ is shown as a function of particle diameter rather than size parameter, and the numbers are presented in Tables 1 and 2. As can be seen from Table 1, the discrepancies between the measured and calculated values increase with GA shell size. However, from Table 2, it can be seen that maintaining a thin GA shell while varying the nigrosin core size leads to excellent agreement between measured and calculated values. A possible reason for the observed discrepancies between the measured and calculated values is that as the shell size increases, the GA crystallizes unevenly on the nigrosin core causing the particle to no longer be perfectly spherical, an effect we explore theoretically in Sect. 4. In order to remedy this possibility, we repeated the experiments using a DEHS shell, which is liquid at room temperature and would not deform the initial shape of the particle. 
Table 1. Calculated and measured extinction efficiencies $\left(Q_{\text {ext }}\right)$ as function of core size (expressed as diameter), coated size, and the coated size parameter for nigrosin (300-nm diameter) coated with various thickness of glutaric acid shell. The standard deviation for the measured values and the percentage error between measured and calculated values are also presented.

\begin{tabular}{ccccccc}
\hline Nigrosin size $(\mathrm{nm})$ & Nigrosin and GA $(\mathrm{nm})$ & Size parameter $(x)$ & $Q_{\text {ext }}$ Calculated & $Q_{\text {ext }}$ measured & STD & Percentage error $\%$ \\
\hline 300 & 311 & 1.84 & 2.380 & 2.437 & 0.023 & 2.3 \\
300 & 322 & 1.90 & 2.355 & 2.302 & 0.023 & 2.3 \\
300 & 334 & 1.97 & 2.333 & 2.201 & 0.059 & 6.0 \\
300 & 346 & 2.04 & 2.316 & 2.102 & 0.076 & 10.2 \\
300 & 359 & 2.12 & 2.304 & 2.127 & 0.070 & 8.3 \\
300 & 372 & 2.20 & 2.299 & 2.160 & 0.065 & 6.5 \\
300 & 385 & 2.27 & 2.304 & 2.162 & 0.066 & 6.6 \\
300 & 400 & 2.36 & 2.321 & 2.251 & 0.031 & 3.1 \\
300 & 429 & 2.53 & 2.395 & 2.237 & 0.071 & 7.1 \\
300 & 461 & 2.72 & 2.524 & 2.363 & 0.068 & 6.8 \\
\hline
\end{tabular}

Table 2. Calculated and measured extinction efficiencies $\left(Q_{\text {ext }}\right)$ as function of core size (expressed as diameter), coated size, and the coated size parameter for nigrosin of various sizes coated with a $20-\mathrm{nm}$ glutaric acid shell. The standard deviation for the measured values and the percentage error between measured and calculated values are also presented.

\begin{tabular}{ccccccc}
\hline Nigrosin size $(\mathrm{nm})$ & Nigrosin + GA $(\mathrm{nm})$ & Size parameter $(x)$ & $Q_{\text {ext }}$ calculated & $Q_{\text {ext }}$ measured & STD & Percentage error \% \\
\hline 175 & 195 & 1.15 & 1.014 & 0.966 & 0.015 & 5.0 \\
200 & 220 & 1.23 & 1.310 & 1.307 & 0.089 & 0.3 \\
250 & 270 & 1.59 & 1.929 & 1.956 & 0.040 & 1.4 \\
300 & 320 & 1.89 & 2.359 & 2.302 & 0.024 & 2.5 \\
350 & 366 & 2.16 & 2.690 & 2.626 & 0.062 & 2.4 \\
400 & 420 & 2.48 & 2.967 & 2.896 & 0.026 & 2.4 \\
\hline
\end{tabular}

\subsection{Nigrosin coated with DEHS}

In Fig. 5, the measured extinction efficiency as a function of particle size parameter is shown for pure nigrosin (black dots) along with the corresponding Mie calculation (solid black line), for pure DEHS (red line) along with the corresponding Mie calculation (solid red line), for nigrosin of various sizes coated with a 20-nm DEHS shell (green dots) along with the corresponding Mie calculation (green line), and for 300-nm nigrosin coated with various thicknesses of DEHS (blue dots) along with the corresponding Mie calculation (blue line). In Fig. 6, the measured $Q_{\text {ext }}$ is shown as a function of particle diameter rather than size parameter, and numbers are presented in Tables 3 and 4. From Figs. 5 and 6 , it is clear that the behavior with the DEHS shell is similar to that with the GA shell.

\section{Discussion}

All measured results are bound by the values of $Q_{\text {ext }}$ calculated with the refractive indices of the pure substances comprising the coated particles of the same size. In the range of sizes investigated in this study, the extinction efficiency first decreases and then slowly increases with increasing shell thickness, following the general pattern of the calculations. In general, a coating may increase or decrease the extinction efficiency of an individual particle even if the refractory nature (real refractive index) of the coating is lower than that of the core, as is the case for GA and DEHS, just by changing the overall size of the particle. The latter would occur if the scattering by the particle decreases more than the absorption increases, such that the overall extinction decreases.

The discrepancies between the measured and calculated values for nigrosin coated with GA and DEHS typically increase with shell thickness. When these discrepancies occur, the calculated values are constantly higher than the measured ones. To understand these discrepancies, we have investigated a number of causes related solely to the experimental setup. It was verified that the nigrosin seeds do not evaporate by checking their size before and after passing through the coating apparatus. The possibility that nigrosin may dissolve in GA or DEHS was eliminated because the nigrosin seed particles were dry and solid. (The efficiency of the diffusion dryers was confirmed by measurements and calibrations from both previous and current studies of the extinction efficiencies of ammonium sulphate, glutaric acid, nigrosin, and 


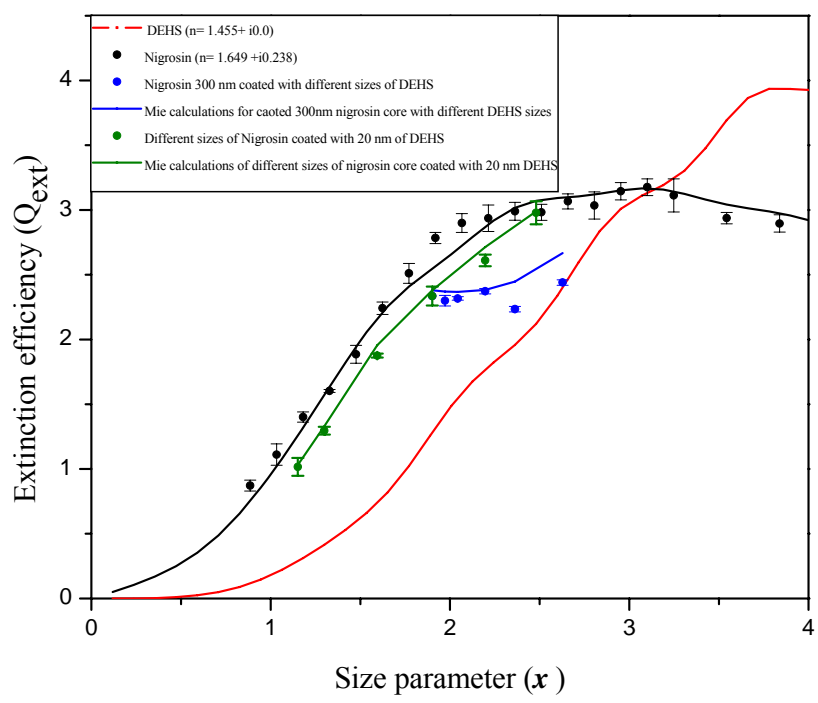

Fig. 5. The measured and calculated extinction efficiencies $\left(Q_{\text {ext }}\right)$ of nigrosin coated with DEHS as a function of size parameter $(x)$.

sodium chloride, which all yielded refractive indices in good agreement with literature values). Particle losses in the cavity and other sensitivity issues of the CRD-AS system likewise cannot account for the discrepancies, as was thoroughly discussed in our previous publications (Riziq et al., 2007). We also ruled out the possibility of evaporation of GA, since as seen in Riziq et al. (2007), the measurements performed with pure and mixed-state glutaric acid are in a very good agreement with the theory. Furthermore, DEHS at $20^{\circ} \mathrm{C}$ has a very low vapor pressure $(<0.007 \mathrm{~mm} \mathrm{Hg})$, and the discrepancies with DEHS are similar to those with GA.

One possible explanation for the discrepancies related to the calculations as well as to the experimental setup is the size distributions used in the measurements. In order to address this issue, we have taken into account the actual size distributions used and added the contribution from the adjacent size bins into the Mie calculations. The results of this addition suggest that including the contribution of the adjacent size bins to the calculated values does not change the results. The percent difference between the values calculated with and without the smaller size bins for nigrosin core size of $300 \mathrm{~nm}$ and coated size $346 \mathrm{~nm}, 400 \mathrm{~nm}$, and $445 \mathrm{~nm}$, is $0.05 \%, 0.07 \%$, and $0.24 \%$, respectively. This is negligible and cannot be the explanation for the observed discrepancies.

A second possible explanation for the discrepancies related to the calculations is that the core plus shell Mie codes exhibit errors for certain core and shell sizes. The only such error mentioned in the literature is ill-conditioning for particles of small overall diameter (Toon and Ackerman, 1981). The particles in this study are not small enough for that to be the source of error. However, it is true that the smaller the particle, the greater the sensitivity of the position of the scattering peaks to changes in the shell thickness (Alexanderkatz,

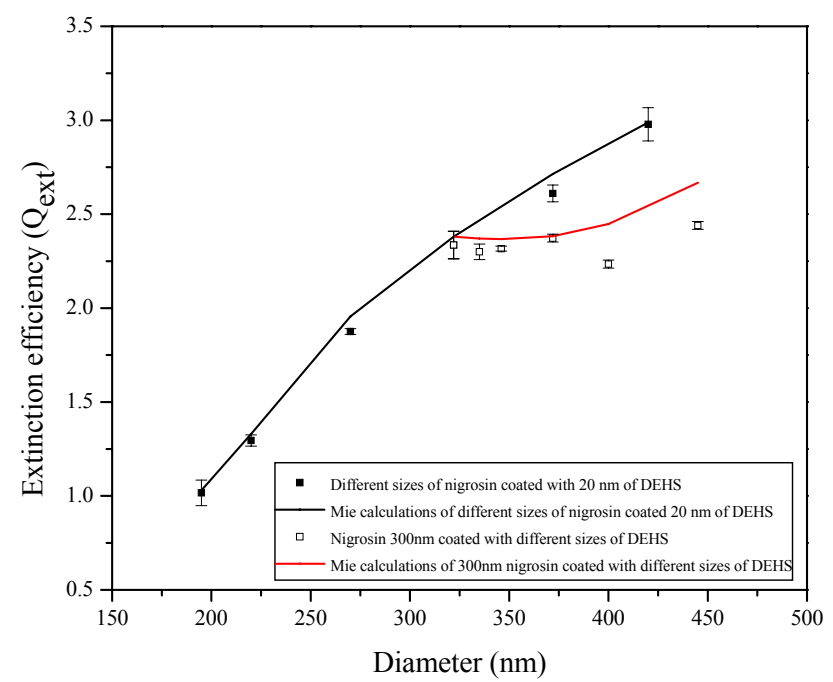

Fig. 6. The measured and calculated extinction efficiencies $\left(Q_{\text {ext }}\right)$ of nigrosin coated with DEHS as a function of particle size (diameter)

1990; Quirantes and Delgado, 2001), so small errors can be exaggerated. Furthermore, we note some similar discrepancies for coated particles comprised of combinations of conducting, semi-conducting, and dielectric materials at other wavelengths, where in some respects the discrepancy there also increases with increasing shell size (Shi et al., 2005, their Fig. 11a-c; Shi et al., 2006, their Fig. 6a-b; Peterson et al., 2007, their Fig. 4a).

A third possible explanation related to the calculations as well as to the experimental setup is that the coated particles in the experiments are not perfectly concentric coated spheres, but instead are not perfectly spherical, have inhomogeneities in the coating (Tu and Ray, 2006). To test whether non-sphericity could account for the discrepancies, LISA, a T-matrix code for randomly oriented coated spheroids, created by A. Quirantes (2005) using the orientation averaging scheme of Mishchenko (1991), was run. Non-sphericity proved not to be an explanation, since the calculated $Q_{\text {ext }}$ for coated spheroids did not vary significantly and was often even greater than the $Q_{\text {ext }}$ calculated for coated spheres, only increasing the discrepancy. For example, for nigrosin coated by GA, core diameter $300 \mathrm{~nm}$, and coated diameter $359 \mathrm{~nm}$, the measured $Q_{\text {ext }}$ was 2.127 , the calculated $Q_{\text {ext }}$ for a coated sphere was 2.304 , and the calculated $Q_{\text {ext }}$ for randomly oriented coated spheroids with eccentricity (ratio of one spheroidal axis to the axis of revolution) $0.7-1.3$ ranged from 2.303 to 2.307. Furthermore, AFM measurements of collected particles prove that the particles are spherical (see Fig. 7). The AFM measurement, however, cannot determine whether the particles are perfectly concentric. (See the discussion of non-concentric coated particles later in this section.) 
Table 3. Calculated and measured extinction efficiencies $\left(Q_{\text {ext }}\right)$ as function of core size (expressed as diameter), coated size, and the coated size parameter for nigrosin (300-nm diameter) coated with various thicknesses of DEHS shells. The standard deviation for the measured values and the percentage error between measured and calculated values are also presented.

\begin{tabular}{ccccccc}
\hline Nigrosin size $(\mathrm{nm})$ & Nigrosin and DEHS $(\mathrm{nm})$ & Size parameter $(x)$ & $Q_{\text {ext }}$ calculated & $Q_{\text {ext }}$ measured & STD & Percentage error $\%$ \\
\hline 300 & 322 & 1.90 & 2.336 & 2.380 & 0.073 & 1.88 \\
300 & 335 & 1.97 & 2.300 & 2.371 & 0.041 & 2.99 \\
300 & 346 & 2.04 & 2.317 & 2.367 & 0.013 & 2.14 \\
300 & 372 & 2.20 & 2.373 & 2.383 & 0.021 & 0.42 \\
300 & 400 & 2.36 & 2.234 & 2.447 & 0.021 & 8.71 \\
300 & 445 & 2.63 & 2.440 & 2.667 & 0.021 & 8.51 \\
\hline
\end{tabular}

Table 4. Calculated and measured extinction efficiencies $\left(Q_{\text {ext }}\right)$ as function of core size (expressed as diameter), coated size, and the coated size parameter for nigrosin of various sizes coated with a 20-nm DEHS shell. The standard deviation for the measured values and the percentage error between measured and calculated values are also presented.

\begin{tabular}{ccccccc}
\hline Nigrosin diameter $(\mathrm{nm})$ & Nigrosin + DEHS $(\mathrm{nm})$ & Size parameter $(x)$ & $Q_{\text {ext }}$ calculated & $Q_{\text {ext }}$ measured & STD & Percentage error \% \\
\hline 175 & 195 & 1.15 & 1.016 & 1.030 & 0.068 & 1.3 \\
200 & 220 & 1.30 & 1.295 & 1.330 & 0.030 & 2.6 \\
250 & 270 & 1.60 & 1.876 & 1.956 & 0.015 & 4.1 \\
300 & 320 & 1.90 & 2.336 & 2.380 & 0.073 & 1.9 \\
350 & 370 & 2.19 & 2.610 & 2.715 & 0.045 & 3.8 \\
400 & 420 & 2.48 & 2.978 & 2.989 & 0.089 & 0.4 \\
\hline
\end{tabular}

To test whether inhomogeneities in the coating could account for the discrepancies, the coating was modeled as a mixture of coating and core material using the MaxwellGarnett mixing rule (see, e.g., Bohren and Huffman, 1983) based on the cluster coupling theory of Rohde et al. (2006), i.e., as if the coating has "holes" in which the core material "peeks through". We also tested a linear combination of dielectric constants of the coating and core according to Eq. (2) in Rohde et al. (2006). Since nigrosin is more refractive than GA or DEHS (even though nigrosin also absorbs), the calculated $Q_{\text {ext }}$ for the inhomogeneous coating were again greater than for homogeneous coatings, which again only increases the discrepancy between the measurements and calculations.

Another calculation for inhomogeneous coatings, based on the idea that the dielectric constant of a thin film is much less near the interface to the core than the bulk coating value (Friedman, 1998; Oates et al., 2004), was also performed. The model for this, based on Friedman (1998, his Eq. 15), describes the decrease in dielectric constant (from the outer surface of the coating to the interface) as exponential, with the average dielectric constant of the coating being the geometric mean of the values throughout the coating:

$\overline{\varepsilon_{\text {coat }}}=\frac{d_{\text {coat }} \varepsilon_{\max }}{d_{\text {coat }}+\frac{1}{k} \ln \left[\frac{\varepsilon_{\max }-\left(\varepsilon_{\max }-\varepsilon_{\min }\right) e^{-k d_{\text {coat }}}}{\varepsilon_{\min }}\right]}$,

where $\overline{\varepsilon_{\text {coat }}}$ is the average dielectric constant of the coating, $d_{\text {coat }}$ is the coating thickness, $\varepsilon_{\max }$ is the original bulk dielectric constant of the coating, $\varepsilon_{\min }$ is the minimum value of the dielectric constant of the coating, and $k$ is an e-folding parameter. The value for $\varepsilon_{\min }$ used in Friedman (1998) is an estimate of the effect of relaxation of the rotation of the polar molecules in the coating (at microwave wavelengths) caused by the bonds between coating and the core material. While we are not dealing with microwave wavelengths in this study, the bonds between a thin film and a substrate have been theorized to cause damping in a number of other situations as well, e.g.: friction in the flow of electrons in conducting and semi-conducting thin films (Lazarev et al., 2003), damping of the alignment of dipoles in ferroelectric and anti-ferroelectric thin films (Wesselinowa, 2005; Wesselinowa and Trimper, 2004), damping of molecular vibrations in thin films at infrared wavelengths (Chu, 1993), and damping of dipole vibration near the surface of a waveguide (LaFortune and Hall, 2002). For lack of specific data on damping in our system, we chose a reduction in the dielectric constant of our coating of similar relative magnitude to that used in Friedman (1998) $\left(k=10^{8} \mathrm{~cm}^{-1}, \varepsilon_{\min }=1.05\right)$. This resulted in a decrease in the calculated $Q_{\text {ext }}$. However, the decrease, while not uniform, occurred for all sizes and not especially as the coating thickness increased (see Table 5). For nigrosin coated by GA, core diameter $300 \mathrm{~nm}$, and coated diameter $359 \mathrm{~nm}$, the measured $Q_{\text {ext }}$ was 2.127 , the calculated $Q_{\text {ext }}$ for a coated sphere with 

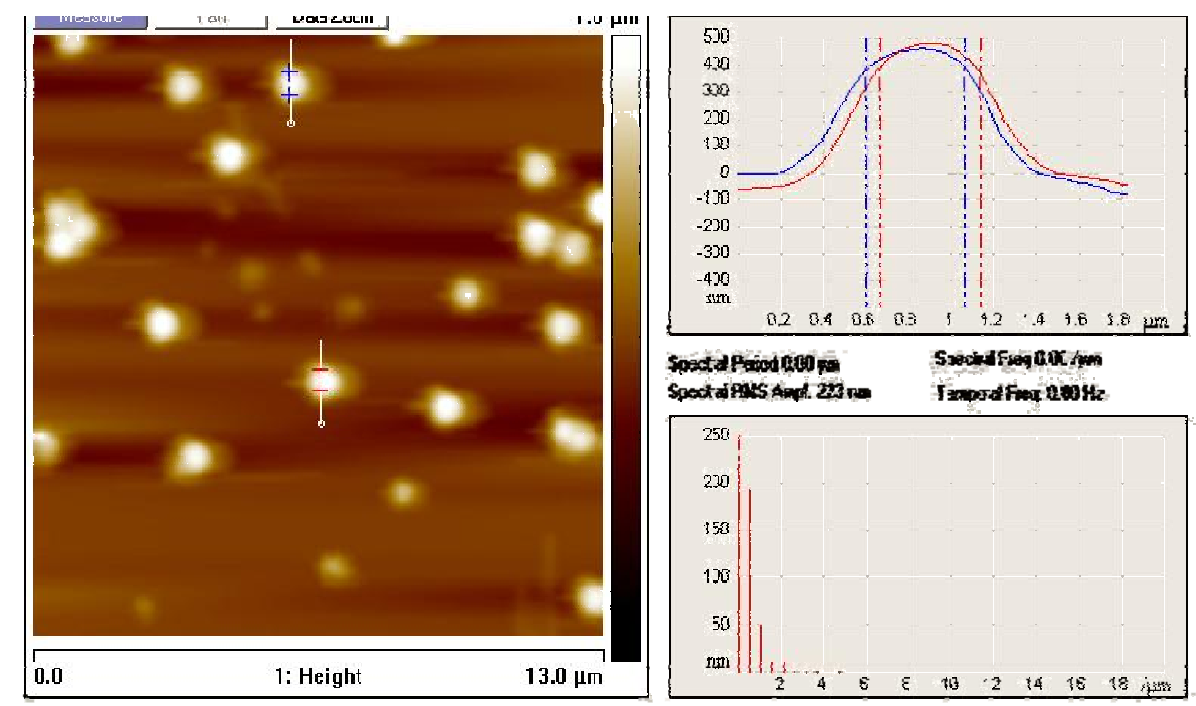

Fig. 7. AFM image of 300-nm nigrosin coated with a 100-nm DEHS shell (400-nm particle diameter). The sample is taken from stage 7 of the MOUDI impactor. The particles are spherical, as can see by the upper right side of this figure (height $=400 \mathrm{~nm}$, width $=\sim 400 \mathrm{~nm}$ ).

the original real refractive index was 2.304 , and the calculated $Q_{\text {ext }}$ for a coated sphere with the adjusted real refractive index is 2.301 . Even if we take $\varepsilon_{\min }$ to be that of a vacuum (1.0) and reduce the e-folding parameter $k$ by an order of magnitude (to $10^{7} \mathrm{~cm}^{-1}$ ), the calculated $Q_{\text {ext }}$ for nigrosin coated by GA, core diameter $300 \mathrm{~nm}$, and coated diameter $359 \mathrm{~nm}$ with the adjusted real refractive index comes out to 2.280. Therefore this effect is at most a partial explanation for the discrepancies.

Tu and Ray (2006) found that static layered droplets are dominantly non-concentric with the lack of concentricity causing a definite signature in the scattered intensity. Ngo and Pinnick (1994) and Prabhue et al. (2001) also showed the effect of non-concentricity on the scattering pattern. Chýlek and Hallett (1992), Videen et al. (1994), Fuller (1995), Borghese et al. (1998), Fuller et al. (1995), and Ioannidou et al. (2000) demonstrated a non-monotonic effect of nonconcentricity on absorption by layered particles, where varying the distance of the core from the center causes fluctuations in the absorption, increasing or decreasing depending on whether the position of the core falls in an absorption "hot spot" of the drop. To test whether a lack of concentricity between the core and coating could account for the discrepancies in the current system, two Mie scattering codes for nonconcentric coated spheres were run, a code in which the shift in the core location is along the line of the incoming radiation (Griaznov et al., 2004), and adei.f, a code allowing any position of the core within the drop (Ngo et al., 1996). The calculation for randomly positioned cores at a given distance of the core from the center was achieved using adei.f and Fuller (1995) (his Eq. 29): $\overline{Q_{\text {ext }}}=\frac{1}{2} \int_{0}^{\pi} Q_{\text {ext }}(\alpha) \sin \alpha d \alpha$, where $\alpha$ is the angle between the direction of incoming radiation and the direction of the shift in the core's location (see Fuller,
1995, his Fig. 14). While the effect of non-concentricity on absorption is non-monotonic, the effect of non-concentricity on $Q_{\text {ext }}$ is found to be monotonic, although $Q_{\text {ext }}$ may monotonically increase or monotonically decrease with a shift in core position (see Table 6). As with the effect described in the previous paragraph, non-concentricity is at most a partial explanation for the discrepancies. For example, for nigrosin coated by GA, core diameter $300 \mathrm{~nm}$ and coated diameter $359 \mathrm{~nm}$, the measured $Q_{\text {ext }}$ was 2.127 , the calculated $Q_{\text {ext }}$ for a concentric coated sphere was 2.304, and the calculated $Q_{\text {ext }}$ for a non-concentric coated sphere with random core position was 2.296. Furthermore, as mentioned earlier, we currently have no means of examining whether non-concentricity occurred in the coated particles we produced.

\section{Conclusions}

Coated particles have been observed in the atmosphere in many field studies. This study tested whether core-shell Mie codes that calculate extinction for such particles adequately model their interaction with radiation in the case of absorbing particles coated by a layer of non-absorbing organic material. In order to study the optical effect of particle coatings in a manner that can be tested against a Mie scattering code, we used nigrosin, an absorbing organic dye that produces spherical core particles, and coated it with two non-absorbing substances, glutaric acid (solid) and DEHS (liquid), to form spherical particles with a core-shell morphology.

In general, the measured values of extinction efficiency for the coated particles corresponded well to the Mie calculations for thin coatings of $10-20 \mathrm{~nm}$. However, there are discrepancies (up to $10 \%$ ) between the measured and calculated 
Table 5. Calculations of $Q_{\text {ext }}$ for GA on nigrosin with real refractive index of GA adjusted according to Friedman (1998), his Eq. (15).

\begin{tabular}{|c|c|c|c|c|c|c|c|c|}
\hline $\begin{array}{l}\text { Nigrosin } \\
\text { size }(\mathrm{nm})\end{array}$ & $\begin{array}{l}\text { Nigrosin and } \\
\text { GA (nm) }\end{array}$ & $\begin{array}{l}\text { Original } \\
\text { RI of GA }\end{array}$ & $\begin{array}{c}\text { Original Calculated } \\
Q_{\text {ext }}\end{array}$ & $\begin{array}{l}\text { Percentage } \\
\text { error } \%\end{array}$ & $\begin{array}{l}\text { Adjusted RI } \\
\text { of coating }\end{array}$ & $\begin{array}{c}\text { Calculated } Q_{\text {ext }} \\
\text { with adjusted index }\end{array}$ & $\begin{array}{c}\text { Measured } \\
Q_{\text {ext }}\end{array}$ & $\begin{array}{l}\text { Percentage error } \% \\
\text { with adjusted index }\end{array}$ \\
\hline 300 & 311 & 1.410 & 2.380 & 2.34 & 1.402 & 2.378 & 2.437 & 2.81 \\
\hline 300 & 322 & 1.410 & 2.356 & 2.31 & 1.406 & 2.353 & 2.302 & 1.85 \\
\hline 300 & 334 & 1.410 & 2.333 & 5.97 & 1.407 & 2.330 & 2.201 & 5.25 \\
\hline 300 & 346 & 1.410 & 2.316 & 10.17 & 1.408 & 2.313 & 2.070 & 10.26 \\
\hline 300 & 359 & 1.410 & 2.304 & 8.33 & 1.408 & 2.301 & 2.127 & 7.29 \\
\hline 300 & 372 & 1.410 & 2.300 & 6.47 & 1.409 & 2.297 & 2.160 & 5.68 \\
\hline 300 & 385 & 1.410 & 2.304 & 6.57 & 1.409 & 2.302 & 2.162 & 5.77 \\
\hline 300 & 400 & 1.410 & 2.321 & 3.13 & 1.409 & 2.319 & 2.251 & 2.60 \\
\hline 300 & 429 & 1.410 & 2.395 & 7.08 & 1.409 & 2.392 & 2.237 & 6.17 \\
\hline 300 & 461 & 1.410 & 2.524 & 6.12 & 1.409 & 2.521 & 2.363 & 5.94 \\
\hline
\end{tabular}

Table 6. Calculations of $Q_{\text {ext }}$ for GA on nigrosin assuming non-concentric coated spheres in the most extreme configuration, i.e., the core situated at the inside edge of the drop.

\begin{tabular}{|c|c|c|c|c|c|c|c|c|}
\hline $\begin{array}{c}\text { Core } \\
\text { diameter } \\
(\mathrm{nm})\end{array}$ & $\begin{array}{l}\text { Coated } \\
\text { diameter } \\
(\mathrm{nm})\end{array}$ & $\begin{array}{c}\text { Original } \\
\text { calculated } \\
Q_{\text {ext }}\end{array}$ & $\begin{array}{c}\text { Original } \\
\% \\
\text { difference }\end{array}$ & $\begin{array}{c}\text { Calculated } \\
Q_{\text {ext for }} \\
\text { aligned core }\end{array}$ & $\begin{array}{l}\text { Calculated } Q_{\text {ext }} \\
\text { for randomly } \\
\text { positioned core }\end{array}$ & $\begin{array}{c}\text { Measured } \\
Q_{\text {ext }}\end{array}$ & $\begin{array}{c}\% \text { Difference } \\
\text { with aligned } \\
\text { core }\end{array}$ & $\begin{array}{l}\% \text { Difference } \\
\text { with randomly } \\
\text { positioned core }\end{array}$ \\
\hline 300 & 311 & 2.380 & 2.3 & 2.380 & 2.379 & 2.437 & 2.3 & 2.45 \\
\hline 300 & 322 & 2.355 & 2.3 & 2.355 & 2.353 & 2.302 & 2.3 & 2.2 \\
\hline 300 & 334 & 2.333 & 6.0 & 2.334 & 2.329 & 2.201 & 6.0 & 5.8 \\
\hline 300 & 346 & 2.316 & 10.2 & 2.319 & 2.310 & 2.070 & 12.0 & 11.6 \\
\hline 300 & 359 & 2.304 & 8.3 & 2.312 & 2.296 & 2.127 & 8.7 & 8.0 \\
\hline 300 & 372 & 2.300 & 6.5 & 2.314 & 2.292 & 2.160 & 7.2 & 6.1 \\
\hline 300 & 385 & 2.304 & 6.6 & 2.328 & 2.297 & 2.162 & 7.7 & 6.3 \\
\hline 300 & 400 & 2.321 & 3.1 & 2.356 & 2.319 & 2.251 & 4.7 & 3.0 \\
\hline 300 & 429 & 2.395 & 7.1 & 2.446 & 2.404 & 2.237 & 9.4 & 7.5 \\
\hline 300 & 461 & 2.524 & 6.12 & 2.564 & 2.548 & 2.363 & 8.5 & 7.8 \\
\hline
\end{tabular}

extinction efficiencies that increase with increasing coating thickness. In an effort to understand these discrepancies, we examined a number of possible effects, none of which provided a full explanation. Evaporation of the nigrosin seeds, dissolution of the nigrosin seeds in the coating, particle losses in the cavity, and evaporation of the coating were all ruled as negligible. The contribution from smaller size bins was also found negligible. Errors in the core plus shell Mie codes for certain core and shell sizes were found to be irrelevant. Calculations of extinction efficiency for randomly oriented coated spheroids only increased the discrepancies, as did calculations of extinction efficiency for coated spheres with inhomogeneities in the coating. Two effects that reduced the calculated extinction efficiency, thereby reducing the discrepancies were (1) the idea that the dielectric constant of a thin film is lower near the interface to the core than the bulk coating value, and (2) the possibility that the shell is not perfectly concentric around the core. However, neither of these effects brought the calculations into exact agreement with the measurements. Our results imply that the Mie codes can be applied for thin coatings, which are probably common in the atmosphere (Falkovich et al., 2004; Maria et al., 2004; Russell et al., 2002), but for thicker coatings, as were observed for some cases of dust (Falkovich et al., 2004; Laskin et al., 2005) and soot (Res et al., 2006), such calculations induce errors in the order of less than $10 \%$.

For future study, we suggest further examination of particle eccentricity. In addition, we intend to measure the optical properties of non-absorbing cores with absorbing shells in order to see, among other things, whether these discrepancies persist.

Acknowledgements. The authors thank S. Cohen and A. Bitler for help with the AFM imaging and analysis and to T. Mentel for supplying the coating apparatus. CE wishes to thank M. Mishchenko and S. Friedman for references on codes for inhomogeneous coated spheres, A. Quirantes for instruction on the code for coated spheroids, I. Veselovskii for providing the code for aligned non-concentric coated spheres, H.-Z. Krugliak for assistance with compiling the code for randomly oriented non-concentric coated 
spheres, and M. Haspel for helpful discussions on extinction. This work was supported by the Israel Science Foundation Grant $1527 / 07$ and by GIF, the German Israeli Science Foundation for Scientific Research and Development, Contract No. I-899228.10/2005. Partial support from the Nancy and Stephen Grand Center for Sensors and Security is acknowledged.

Edited by: V. F. McNeill

\section{References}

Alexanderkatz, R.: Scattering pattern of a quasitransparent coreshell particle, Phys. Rev. A., 42, 6816-6822, 1990.

Bohren, C. F. and Huffman, D. R.: Absorption and scattering of light by small particles, 530 pp., Wiley, 1983.

Bond, T. C. and Bergstrom, R. W.: Light absorption by carbonaceous particles: An investigative review, Aerosol Sci. Tech., 40, 27-67, 2006.

Borghese, F., Denti, P., Saija, R., Iati, M. A., and Sindoni, O. I.: Optical resonances of spheres containing an eccentric spherical inclusion, J. Opt., 29, 28-34, 1998.

Chung, S. H. and Seinfeld, J. H.: Global distribution and climate forcing of carbonaceous aerosols, J. Geophys. Res.-Atmos., 107, 4407, doi:4410.1029/2001JD001397, 2002.

Chýlek, P. and Hallett, J.: Enhanced absorption of solar-radiation by cloud droplets containing soot particles in their surface, Q. J. Roy. Meteor. Soc., 118, 167-172, 1992.

Chýlek, P., Lesins, G. B., Videen, G., Wong, J. G. D., Pinnick, R. G., Ngo, D., and Klett, J. D.: Black carbon and absorption of solar radiation by clouds, J. Geophys. Res.-Atmos., 101, 23 365$23371,1996$.

Dinar, E., Riziq, A. A., Spindler, C., Erlick, C., Kiss, G., and Rudich, Y.: The complex refractive index of atmospheric and model humic-like substances (HULIS) retrieved by a cavity ring down aerosol spectrometer (CRD-AS), Faraday Discuss., 137, 279-295, 2008.

Falkovich, A. H., Schkolnik, G., Ganor, E., and Rudich, Y.: Adsorption of organic compounds pertinent to urban environments onto mineral dust particles, J. Geophys. Res.-Atmos., 109, D01201, doi:01210.01029/02003JD003919, 2004.

Forster, P., Ramaswamy, V., Artaxo, P., Berntsen, T., Betts, R., Fahey, D. W., Haywood, J., Lean, J., Lowe, D. C., Myhre, G., Nganga, J., Prinn, R., Raga, G., Schulz, M., and Van Dorland, R.: Changes in Atmospheric Constituents and in Radiative Forcing, in: Climate Change 2007: The Physical Science Basis. Contribution of Working Group I to the Fourth Assessment Report of the Intergovernmental Panel on Climate Change, edited by: Solomon, S., Qin, D., Manning, M., Chen, Z., Marquis, M., Averyt, K. B., Tignor, M., and Miller, H. L., Cambridge University Press, Cambridge, 160-170, 2007.

Friedman, S. P.: A saturation degree-dependent composite spheres model for describing the effective dielectric constant of unsaturated porous media, Water Resour. Res., 34, 2949-2961, 1998.

Fuller, K. A.: Scattering and absorption cross-sections of compounded spheres, 3, Spheres containing arbitrarily aocated spherical inhomogeneities, J. Opt. Sci. Am. A., 12, 893-904, 1995.

Fuller, K. A., Malm, W. C., and Kreidenweis, S. M.: Effects of mixing on extinction by carbonaceous particles, J. Geophys. Res.Atmos., 104, 15 941-15 954, 1999.
Garvey, D. M. and Pinnick, R. G.: Response Characteristics Of The Particle Measuring Systems Active Scattering Aerosol Spectrometer Probe (Asasp-X), Aerosol Sci. Tech., 2, 477-488, 1983.

Gelencser, A.: Carbonaceous Aerosol, Springer, 352 pp., 2004.

Goodman, A. L., Underwood, G. M., and Grassian, V. H.: A laboratory study of the heterogeneous reaction of nitric acid on calcium carbonate particles, J. Geophys. Res.-Atmos., 105, 29053 $29064,2000$.

Griaznov, V., Veselovskii, I., Di Girolamo, P., Demoz, B., and Whiteman, D. N.: Numerical simulation of light backscattering by spheres with off-center inclusion. Application to the lidar case, Appl. Optics, 43, 5512-5522, 2004.

Guazzotti, S. A., Whiteaker, J. R., Suess, D., Coffee, K. R., and Prather, K. A.: Real-time measurements of the chemical composition of size-resolved particles during a Santa Ana wind episode, California USA, Atmos. Environ., 35, 3229-3240, 2001.

Ioannidou, M. P., Bakatsoula, I. I., and Chrissoulidis, D. P.: Light scattering and absorption by soot in the presence of sulfate aerosols, Appl. Optics, 39, 4205-4213, 2000.

Jacobson, M. Z.: A physically-based treatment of elemental carbon optics: Implications for global direct forcing of aerosols, Geophys. Res. Lett., 27, 217-220, 2000.

Kaufman, Y. J. and Fraser, R. S.: The effect of smoke particles on clouds and climate forcing, Science, 277, 1636-1639, 1997.

Kaufman, Y. J., Tanre, D., and Boucher, O.: A satellite view of aerosols in the climate system, Nature, 419, 215-223, 2002.

Kirchstetter, T. W., Novakov, T., and Hobbs, P. V.: Evidence that the spectral dependence of light absorption by aerosols is affected by organic carbon, J. Geophys. Res.-Atmos., 109, D21208, doi:21210.21029/22004JD004999, 2004.

Koren, I., Kaufman, Y. J., Rosenfeld, D., Remer, L. A., and Rudich, Y.: Aerosol invigoration and restructuring of Atlantic convective clouds, Geophys. Res. Lett., 32, L14828, doi:14810.11029/12005GL023187, 2005.

Kousaka, Y., Endo, Y., Alonso, M., Ichitsubo, H., and Fukui, A.: Nanometer Coating On Aerosol-Particles, Adv. Powder Tech., 6, 11-24, 1995.

Krueger, B. J., Grassian, V. H., Cowin, J. P., and Laskin, A.: Heterogeneous chemistry of individual mineral dust particles from different dust source regions: the importance of particle mineralogy, Atmos. Environ., 38, 6253-6261, 2004.

Krueger, B. J., Grassian, V. H., Laskin, A., and Cowin, J. P.: The transformation of solid atmospheric particles into liquid droplets through heterogeneous chemistry: Laboratory insights into the processing of calcium containing mineral dust aerosol in the troposphere, Geophys. Res. Lett., 30, 1148, doi:1110.1029/2002GL016563, 2003.

Lack, D. A., Lovejoy, E. R., Baynard, T., Pettersson, A., and Ravishankara, A. R.: Aerosol absorption measurement using photoacoustic spectroscopy: Sensitivity, calibration, and uncertainty developments, Aerosol Sci. Tech., 40, 697-708, 2006.

LaFortune, K. N. and Hall, D. G.: Dipole-waveguide coupling in nonlinear systems, J. Opt. Soc. Am. B, 19, 860-869, 2002.

Laskin, A., Iedema, M. J., Ichkovich, A., Graber, E. R., Taraniuk, I., and Rudich, Y.: Direct observation of completely processed calcium carbonate dust particles, Faraday Discuss., 130, 453468, 2005.

Lazarev, S., Mirjanic, D., Mitranic, L., and Pantic, M.: Dielectric properties of ultrathin films of molecular crystals, J. Phys. Chem. 
Solids, 64, 715-722, 2003.

Lesins, G., Chýlek, P., and Lohmann, U.: A study of internal and external mixing scenarios and its effect on aerosol optical properties and direct radiative forcing, J. Geophys. Res.-Atmos., 107, 4094, doi:4010.1029/2001JD000973, 2002.

Maria, S. F., Russell, L. M., Gilles, M. K., and Myneni, S. C. B.: Organic aerosol growth mechanisms and their climate-forcing implications, Science, 306, 1921-1924, 2004.

Mishchenko, M. I.: Light-scattering by randomly oriented axially symmetrical particles, J. Opt. Sci. Am. A., 8, 871-882, 1991.

Ngo, D. and Pinnick, R. G.: Suppression of scattering resonances in inhomogeneous microdroplets, J. Opt. Sci. Am. A., 11, 13521359, 1994.

Ngo, D., Videen, G., and Chýlek, P.: A FORTRAN code for the scattering of EM waves by a sphere with a nonconcentric spherical inclusion, Comp. Phys. Comm., 99, 94-112, 1996.

Oates, T. W. H., McKenzie, D. R., and Bilek, M. M. M.: Percolation threshold in ultrathin titanium films determined by in situ spectroscopic ellipsometry, Phys. Rev. B, 70, 1-6, 2004.

Peterson, M. S. M., Bouwman, J., Chen, A. Q., and Deutsch, M.: Inorganic metallodielectric materials fabricated using two singlestep methods based on the Tollen's process, J. Colloid Interf. Sci., 306, 41-49, 2007.

Pettersson, A., Lovejoy, E. R., Brock, C. A., Brown, S. S., and Ravishankara, A. R.: Measurement of aerosol optical extinction at $532 \mathrm{~nm}$ with pulsed cavity ring down spectroscopy, J. Aerosol Sci., 35, 995-1011, 2004.

Prabhu, D. R., Davies, M., and Videen, G.: Light scattering calculations from oleic-acid droplets with water inclusions, Optics Express, 8, 308-313, 2001.

Quirantes, A.: A T-matrix method and computer code for randomly oriented, axially symmetric coated scatterers, J. Quant. Spectros. Ra., 92, 373-381, 2005.

Quirantes, A. and Delgado, A. V.: Scattering cross sections of randomly oriented coated spheroids, J. Quant. Spectros. Ra., 70, 261-272, 2001

Ramanathan, V., Chung, C., Kim, D., Bettge, T., Buja, L., Kiehl, J. T., Washington, W. M., Fu, Q., Sikka, D. R., and Wild, M.: Atmospheric brown clouds: Impacts on South Asian climate and hydrological cycle, Proc. Natl. Acad. Sci. USA, 102, 5326-5333, 2005.

Ramanathan, V., Ramana, M. V., Roberts, G., Kim, D., Corrigan, C., Chung, C., and Winker, D.: Warming trends in Asia amplified by brown cloud solar absorption, Nature, 448, 575-U575, 2007.

Res, J. G., Schwarz, J. P., Gao, R. S., Fahey, D. W., Thomson, D. S., Watts, L. A., Wilson, J. C., Reeves, J. M., Darbeheshti, M., Baumgardner, D. G., Kok, G. L., Chung, S. H., Schulz, M., Hendricks, J., Lauer, A., Karcher, B., Slowik, J. G., Rosenlof, K. H., Thompson, T. L., Langford, A. O., Loewenstein, M., and Aikin, K. C.: Single-particle measurements of midlatitude black carbon and light-scattering aerosols from the boundary layer to the lower stratosphere, J. Geophys. Res.-Atmos., 111, D16207, doi:10.1029/2006JD007076, 2006.
Riziq, A. A., Erlick, C., Dinar, E., and Rudich, Y.: Optical properties of absorbing and non-absorbing aerosols retrieved by cavity ring down (CRD) spectroscopy, Atmos. Chem. Phys., 7, 15231536, 2007, http://www.atmos-chem-phys.net/7/1523/2007/.

Rohde, C. A., Hasegawa, K., and Deutsch, M.: Coherent light scattering from semicontinuous silver nanoshells near the percolation threshold, Phys. Rev. Lett., 96, 045503, 045503-045501 to 045504, 2006.

Roselli, D.: Development and test of a system for simultaneous measurement of hygroscopic properties and chemical composition of multi-component aerosols, Univerista degli Studi "Carlo Bo" of Urbino, Urbino, Italy, 2006.

Russell, L. M., Maria, S. F., and Myneni, S. C. B.: Mapping organic coatings on atmospheric particles, Geophys. Res. Lett., 29, 1779, doi:10.1029/2002GL014874, 2002.

Shi, W. L., Sahoo, Y., Swihart, M. T., and Prasad, P. N.: Gold nanoshells on polystyrene cores for control of surface plasmon resonance, Langmuir, 21, 1610-1617, 2005.

Shi, W. L., Zeng, H., Sahoo, Y., Ohulchanskyy, T. Y., Ding, Y., Wang, Z. L., Swihart, M., and Prasad, P. N.: A general approach to binary and ternary hybrid nanocrystals, Nano Lett., 6, 875881, 2006.

Spindler, C., Abo Riziq, A., and Rudich, Y.: Retrieval of aerosol complex refractive index by combining cavity ring down aerosol spectrometer measurement with full size distribution information, Aerosol Sci. Tech., 41, 1011-1017, 2007.

Sun, H. L., Biedermann, L., and Bond, T. C.: Color of brown carbon: A model for ultraviolet and visible light absorption by organic carbon aerosol, Geophys. Res. Lett., 34, L17813, doi:17810.11029/12007GL029797, 2007.

Toon, O. B. and Ackerman, T. P.: Algorithms for the calculation of scattering sy stratified spheres, Appl. Optics, 20, 3657-3660, 1981.

Tu, H. H. and Ray, A. K.: Investigation of concentrically and eccentrically layered droplets by light scattering, Appl. Optics, 45, 7652-7656, 2006.

Videen, G., Ngo, D., and Chýlek P.: Effective-medium predictions of absorption gy graphitic carbon in water droplets, Optics Lett., 19, 1675-1677, 1994.

Wesselinowa, J. M.: Dielectric function of antiferroelectric thin films, Phys. Status Solidi B, 242, 1528-1536, 2005.

Wesselinowa, J. M. and Trimper, S.: Thickness dependence of the dielectric function of ferroelectric thin films, Phys. Status Solidi B, 241, 1141-1148, 2004.

Zhang, Q., Canagaratna, M. R., Jayne, J. T., Worsnop, D. R., and Jimenez, J. L.: Time- and size-resolved chemical composition of submicron particles in Pittsburgh: Implications for aerosol sources and processes, J. Geophys. Res.-Atmos., 110, D07S09, doi:10.1029/2004JD004649, 2005. 